\title{
Características físico-químicas de frutos de abobrinha -de-moita em função de doses de potássio em cobertura
}

\section{Physico-chemical characteristics of zucchini fruits as a function of potassium top dressing levels}

HUMBERTO SAMPAIO DE ARAÚJ01, 2, 3

ANTONIO ISMAEL INÁCIO CARDOSO ${ }^{1}$

REGINA MARIA EVANGELISTA ${ }^{1}$

WILLIAM HIROSHI SUEKANE TAKATA'

EVERTON GASPARETTO DA SILVA'

Planta de abobrinha-de-moita.

Foto: A.I.I. Cardoso

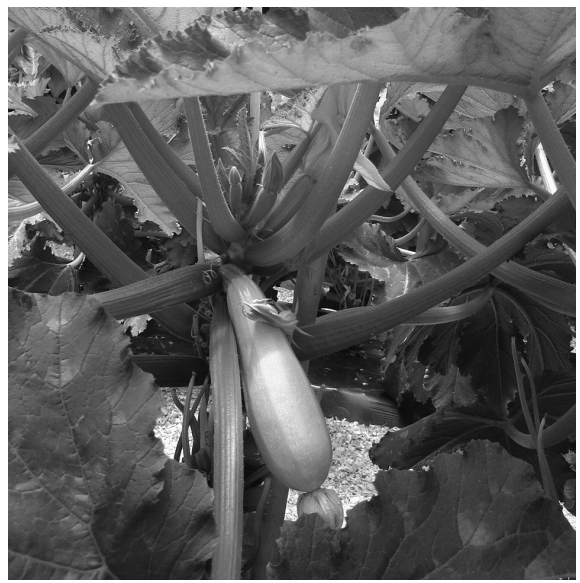

\section{RESUMO}

O potássio é considerado por muitos pesquisadores como o nutriente relacionado à qualidade dos frutos. No entanto, são poucas as pesquisas em que este efeito do potássio é avaliado. Objetivou-se com este trabalho avaliar o efeito de doses de potássio em cobertura na qualidade físico-química de frutos de abobrinha-de-moita (Cucurbita pepo L.) híbrido Aline. Foram avaliados cinco tratamentos (0, 50, 100, 150 e $200 \mathrm{~kg} \mathrm{ha}^{-1}$ de $\mathrm{K}_{2} \mathrm{O}$ em cobertura), no delineamento experimental de blocos casualizados, com quatro repetições. Logo após a colheita dos frutos foram avaliadas as seguintes características físico-químicas: teor de macronutrientes nos frutos, potencial hidrogeniônico (pH), acidez total titulável (ATT), sólidos solúveis totais (SST), "ratio" (relação SST/ATT), porcentagem de açúcares redutores e a textura. O teor de potássio, o pH, e a relação SST/ATT nos frutos aumentaram à medida que se aumentou a dose de potássio, enquanto a acidez total titulável reduziu. As outras características não foram influenciadas pelas doses de potássio.

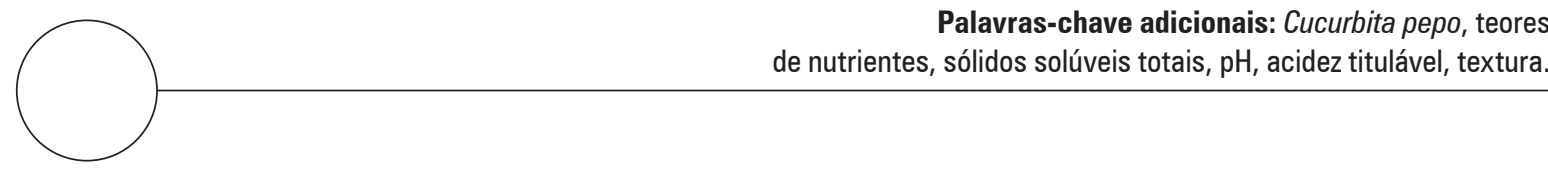

\footnotetext{
Departamento Produção Vegetal, FCA, Universidade Estadual Paulista "Julio de Mesquita Filho", Botucatu-SP (Brasil). Agência Paulista de Tecnologia dos Agronegócios, Andradina-SP (Brasil).

Autor para correspondencia. humbertosaraujo@yahoo.com.br
} 


\section{ABSTRACT}

Potassium is considered by many researchers as the nutrient responsible for fruit quality. However, there are few studies on it. The objective of this study was to evaluate the effect of potassium topdressing levels on the physicochemical characteristics of zucchini fruits (Cucurbita pepo L.), hybrid Aline. Five treatments $(0,50$, 100,200 and $400 \mathrm{~kg} \mathrm{ha}^{-1}$ of $\mathrm{K}_{2} \mathrm{O}$ topdressing) were evaluated in a randomized complete block design with four replications. Soon after the fruit harvest, the following fruit characteristics were evaluated: macronutrient content, hydrogen potential $(\mathrm{pH})$, total titratable acidity (TTA), total soluble solids (TSS), TSS/TTA ratio, percentage of reducing sugars and texture. The potassium content, $\mathrm{pH}$, and TSS/TTA ratio increased in the fruits as the level of potassium increased; whereas, the TTA was reduced. The other characteristics were not influenced by the potassium levels.

Additional key words: Cucurbita pepo, nutrient content, total soluble solids, pH, total titratable acidity, texture.

Fecha de recepción: 29-08-2014

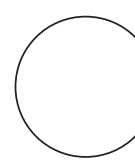

Nos últimos dez anos o consumo de hortaliças no Brasil aumentou de forma considerável, tendo neste período o volume de abobrinha-de-moita (Cucurbita pepo L.) comercializados pela Companhia de Entrepostos e Armazéns Gerais de São Paulo (CEAGESP) um acréscimo de aproximadamente 85\% (Ceagesp, 2014). Juntamente com o aumento do consumo, é crescente a demanda por produtos de qualidade, onde tamanho, coloração, uniformidade, textura da casca e características químicas são valorizados.

O potássio afeta atributos como cor, tamanho, acidez, valor nutritivo e resistência ao transporte, manuseio e armazenamento, sendo considerado um nutriente muito relacionado com a qualidade (Malavolta, 2006). Este nutriente também é responsável pela translocação de açúcares e síntese de amido (Kumar et al., 2007). Por estas razões, estudos relacionando doses à qualidade são complementares aos trabalhos voltados à produção e desenvolvimento vegetativo.

As hortaliças são exigentes em potássio, sendo este o macronutriente mais extraído pela maioria delas. Vidigal et al. (2007) e Araújo et al. (2012) observaram que o potássio foi o nutriente absorvido em maior quantidade pela abóbora de rama, seguido do nitrogênio e cálcio.

Além de influenciar na produtividade, ele melhora a qualidade do produto e, consequentemente, o valor de mercado (Filgueira, 2008). Em melancia (Citrullus lanatus) Grangeiro e Cecìlio Filho (2004) concluíram que o teor de sólidos solúveis totais e a relação entre sólidos solúveis totais e acidez total titulável foram influenciados pelas doses de potássio. Também foram observadas alterações em atributos físico-químicos em função de doses de potássio em pimentão (Melo et al., 2008). Porém, Costa et al. (2004), avaliando a qualidade de frutos de melão (Cucumis melo) em função da concentração de potássio, concluíram que as doses acima de $66 \mathrm{mg} \mathrm{L}^{-1}$ na solução nutritiva não promoveram alteração nas características teor de sólidos solúveis totais e acidez total titulável. Salata et al. (2011), com ervilha de vagem, e Godoy et al. (2012), com couve-flor, não observaram diferença significativa para as características físico-químicas avaliadas com a aplicação de doses de potássio em cobertura. Portanto, apesar do potássio ser considerado por muitos autores como o nutriente mais importante na qualidade das 
hortaliças, não há consenso nas pesquisas já realizadas com diferentes espécies.

No entanto, não foram encontrados trabalhos em abobrinha-de-moita (C. pepo) relacionando as características físico-químicas dos frutos com a adubação das plantas. Diante do exposto, objetivou-se com o presente trabalho estudar a influência de doses de potássio em cobertura nas características físico-químicas dos frutos de abobrinha-de-moita.

\section{MATERIAL E MÉTODOS}

O experimento foi conduzido em São Manuel-SP (2246' S; 48³4' W; altitude média de 740 $\mathrm{m})$ em um solo classificado como Latossolo Vermelho Distrófico Típico. Os resultados obtidos na análise química, na camada de $0-20 \mathrm{~cm}$ de profundidade, antes da instalação do experimento foram: $\mathrm{pH}_{\left(\mathrm{CaCl}_{2}\right)}=6,2 ; \mathrm{P}_{\text {resina }}=15 \mathrm{mg} \mathrm{dm}^{-3}$; matéria orgânica $=10 \mathrm{~g} \mathrm{dm}^{-3} ; \mathrm{V} \%=77 ; \mathrm{H}+\mathrm{Al}$ $=11 \mathrm{mM}_{\mathrm{c}} \mathrm{dm}^{-3} ; \mathrm{K}=1,5 \mathrm{mM}_{\mathrm{c}} \mathrm{dm}^{-3} ; \mathrm{Ca}=25$ $\mathrm{mM}_{\mathrm{c}} \mathrm{dm}^{-3} ; \mathrm{Mg}=10 \mathrm{mM}_{\mathrm{c}} \mathrm{dm}^{-3} ; \mathrm{SB}=37 \mathrm{mM}_{\mathrm{c}}$ $\mathrm{dm}^{-3} ; \mathrm{CTC}=48 \mathrm{mM}_{\mathrm{c}} \mathrm{dm}^{-3}$. $O$ valor obtido para o potássio $\left(1,5 \mathrm{mM}_{\mathrm{c}} \mathrm{dm}^{-3}\right)$ é considerado baixo por Trani e Raij (1997).

Com base na análise química do solo, segundo a recomendação de Trani e Raij (1997), foram realizadas as correções e as adubações de plantio, utilizando $40 \mathrm{~kg} \mathrm{ha}^{-1}$ de nitrogênio, $400 \mathrm{~kg} \mathrm{ha}^{-1}$ de fósforo $\left(\mathrm{P}_{2} \mathrm{O}_{5}\right), 200 \mathrm{~kg} \mathrm{ha}^{-1} \mathrm{de}$ potássio $\left(\mathrm{K}_{2} \mathrm{O}\right)$ e $10 \mathrm{t}$ ha-1 de composto orgânico da marca comercial Provaso ${ }^{\circledR}$. Também foi aplicado $150 \mathrm{~kg} \mathrm{ha}^{-1}$ de nitrogênio em cobertura na forma de uréia $(44 \% \mathrm{~N})$, parceladas em três aplicações, sendo a primeira feita aos $15 \mathrm{~d}$ após o transplantio e as demais espaçadas em quinze dias uma da outra. As dosagens de potássio aplicados em cobertura na forma de cloreto de potássio $\left(58 \% \mathrm{~K}_{2} \mathrm{O}\right)$ foram os tratamentos propostos no presente trabalho. $\bigcirc$ parcelamento $e$ datas das aplicações foram iguais aos utilizados para o nitrogênio.
Para reduzir o erro experimental e a fim de promover o controle local realizou-se o delineamento experimental em blocos ao acaso, com quatro repetições e cinco tratamentos $(0,50$, 100, 200 e $400 \mathrm{~kg}$ de $\mathrm{K}_{2} \mathrm{O} \mathrm{ha}^{-1}$ em cobertura), com oito plantas por parcela, sendo colhidos os frutos de seis plantas úteis por parcela. A dose média recomendada (DR) por Trani e Raij (1997) é de $100 \mathrm{~kg}$ de $\mathrm{K}_{2} \mathrm{O} \mathrm{ha}^{-1}$, sendo que os tratamentos correspondem a $0 ; 0,5 ; 1,0 ; 2,0$ e 4,0 vezes a $\mathrm{DR}$.

Foi utilizado o híbrido de abobrinha-de-moita (C. pepo) cultivar Aline. A semeadura foi feita no dia 04/08/2010 em bandejas de poliestireno expandido de 128 células, contendo fibra de coco para mudas de hortaliças e o transplante foi no dia 25/08/2010, no espaçamento de $1,2 \mathrm{~m}$ entre linhas e 0,5 m entre plantas. A irrigação foi por aspersão e o controle de plantas daninhas foi com capinas. As colheitas iniciaram no dia 29/09/2010 e terminaram no dia 03/11/2010. Ao longo deste período foram colhidos os frutos imaturos de tamanho comercial (aproximadamente $20 \mathrm{~cm}$ de comprimento), que foram levados para o laboratório de fisiologia e pós-colheita de frutas e hortaliças e para o laboratório de análise química de plantas, na Universidade Estadual Paulista Julio de Mesquita Filho, UNESP-Botucatu, onde foram devidamente lavados em água corrente e deionizada e encaminhados para a determinação das seguintes características:

Teor de macronutrientes: inicialmente os frutos foram cortados em rodelas (aproximadamente $0,5 \mathrm{~cm}$ de espessura) e secos em estufa de circulação forçada de ar a $65^{\circ} \mathrm{C}$, até atingirem massa constante. Posteriormente, cada amostra passou pela moagem no moinho tipo Wiley. Foi feita a digestão sulfúrica por via seca para a obtenção do extrato visando a determinação do nitrogênio. A digestão nítrico-perclórica foi utilizada para a obtenção dos extratos para as determinações dos demais nutrientes (fósforo, potássio, cálcio, magnésio e enxofre), conforme 
metodologias apresentadas por Malavolta et al. (1997). Os resultados foram expressos em $\mathrm{g} \mathrm{kg}^{-1}$ de matéria seca.

Potencial hidrogeniônico $(\mathrm{pH})$ : após a trituração dos frutos e homogeneização da massa, foi determinado o $\mathrm{pH}$ pela leitura direta no potenciômetro (Digital DMPH-2, Digimed, São Paulo, Brasil), conforme as normas do Instituto Adolfo Lutz (Brasil, 2005).

Acidez total titulável (ATT): foi determinada por meio da titulação de $5 \mathrm{~g}$ de polpa homogeneizada e diluída para $100 \mathrm{~mL}$ de água destilada, com solução padronizada de hidróxido de sódio a $0,1 \mathrm{~N}$, tendo como indicador a fenolftaleína, que ocorre quando o potenciômetro atinge 8,1 conforme as normas do Instituto Adolfo Lutz, publicadas em Brasil (2005), sendo os resultados expressos em porcentagem (\%).

Sólidos solúveis totais (SST): após a maceração de algumas fatias da polpa dos frutos, foram extraídas duas gotas do suco e colocadas no prisma do refratômetro eletrônico (Atago, modelo PR32 Atago, Ribeirão Preto), e, após um minuto, fez-se a leitura direta em ${ }^{\circ}$ Brix, conforme recomendação feita pela Association of Official Analytical Chemistry (AOAC, 2005).

"Ratio" ou relação entre sólidos solúveis totais e acidez total titulável (SST/ATT): determinada pela divisão do valor de SST pelo da ATT (Chitarra e Chitarra, 2005).

Açúcares redutores: após a trituração dos frutos e homogeneização da massa foi determinado pelo método descrito por Nelson (1944), sendo os resultados expressos em porcentagem (\%).

Textura: foi medida em dois pontos na extremidade de dois frutos inteiros de cada parcela experimental com a utilização do texturômetro (Stevens-LFRA Texture Analyser, Brookfield Engineering, Middleboro, MA), com profundidade de penetração de $20 \mathrm{~mm}$ e velocidade de
2,0 $\mathrm{mm} \mathrm{s}^{-1}$ e ponteiro (TA 9/1000, Brookfield Engineering, Middleboro, MA) sendo os resultados expressos em $\mathrm{N}$.

Os resultados foram submetidos à análise de variância e de regressão, utilizando-se o programa Sisvar.

\section{RESULTADOS E DISCUSSÃO}

Não foram observadas diferenças significativas entre os teores médios de nitrogênio, fósforo, cálcio, magnésio e enxofre nos frutos em função das doses de potássio aplicadas, com médias de 29,55; 5,35; 4,25; 3,99 e 2,35 $\mathrm{g} \mathrm{kg}^{-1}$ de matéria seca, respectivamente. Isto implica dizer que o aumento das doses de potássio não influenciou o teor destes nutrientes nos frutos, mostrando assim neste caso não haver relações entre o potássio e estes nutrientes. No entanto, o aumento das doses de potássio em cobertura proporcionou aumento linear no teor deste macronutriente no fruto, com incremento de 2,89 $\mathrm{g} \mathrm{kg}^{-1}$ de matéria seca para cada $100 \mathrm{~kg}$ de $\mathrm{K}_{2} \mathrm{O}$ $\mathrm{ha}^{-1}$ aplicados em cobertura (figura 1A).

Estes resultados mostram que pode estar havendo consumo de luxo nos frutos, ocasionado por extrações desnecessárias de potássio pelas plantas, conforme descreveu Brady (1989). Por outro lado, considerando-se o fruto como fonte de nutrientes minerais para o ser humano, este maior teor, se não prejudicar a produção e outros atributos de qualidade, pode ser bom Os teores variaram de 30,82 a $42,38 \mathrm{~g} \mathrm{~kg}^{-1}$ (ou seja, 308,2 a 423,8 mg $100 \mathrm{~g}^{-1}$ ). A necessidade diária de potássio para uma pessoa é $2.000 \mathrm{mg}$ (Minerais, 2009). Os teores obtidos neste trabalho correspondem, portanto, a aproximadamente 1/5 das necessidades diárias, considerando-se consumo de $100 \mathrm{~g}$ de abobrinha (Cucurbita pepo).

A ordem decrescente de teores de nutrientes nos frutos foi: $\mathrm{K}>\mathrm{N}>\mathrm{P}>\mathrm{Ca}>\mathrm{Mg}>\mathrm{S}$, semelhante ao relatado por Vidigal et al. (2007) 


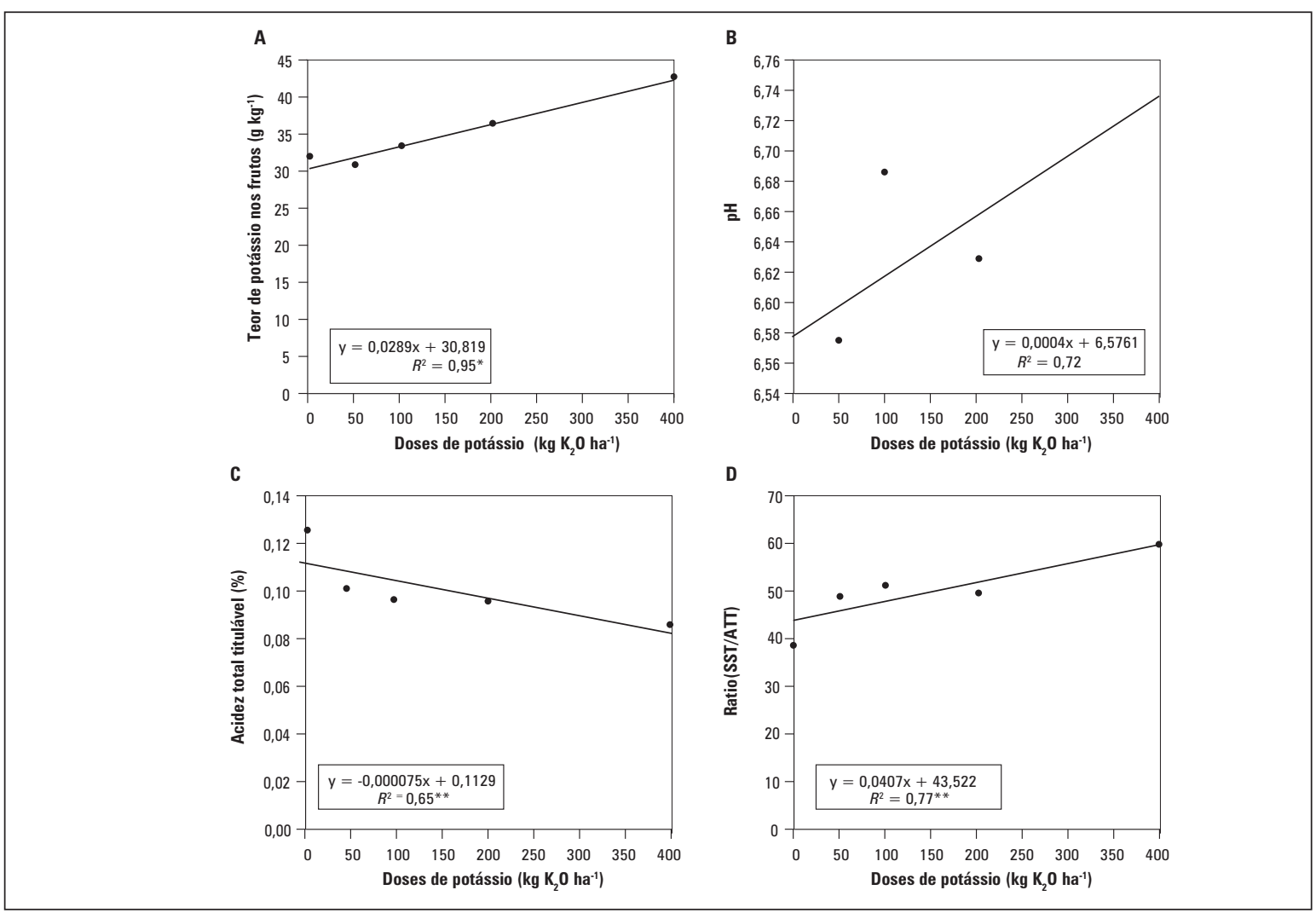

Figura 1. A. Teor de potássio, B. pH, C. Acidez total titulável e D. Ratio nos frutos de abobrinha (Cucurbita pepo) em função das doses de potássio $\left(\mathrm{K}_{2} \mathrm{O}\right)$ aplicado em cobertura.

e Araújo et al. (2012), em abóbora 'Tetsukabuto' e 'Miriam', respectivamente, que relataram a seguinte ordem: $\mathrm{K}>\mathrm{N}>\mathrm{P}>\mathrm{Ca}>\mathrm{S}>\mathrm{Mg}$. Comparando com outras cucurbitáceas percebe-se que o K é o nutriente mais acumulado nos frutos também em melancia (Citrullus lanatus) (Grangeiro e Cecílio Filho, 2004).

aumento das doses de potássio proporcionou aumento linear no $\mathrm{pH}$ dos frutos de abobrinha-de-moita (C. pepo) (figura 1B). Porém, este aumento, apesar de significativo, foi pouco representativo, variando de 6,58 a 6,74 com aumento de 0,04 unidades para cada $100 \mathrm{~kg}$ de $\mathrm{K}_{2} \mathrm{O}$ ha $^{-1}$ aplicados em cobertura. Talvez o acúmulo íons de $\mathrm{K}^{+}$nos frutos resultou na troca catiônica com íons $\mathrm{H}^{+}$resultando assim na elevação do pH dos frutos.

Vásquez et al. (2005) também obtiveram aumento linear de $\mathrm{pH}$ dos frutos de melão C. melo) ao estudarem doses de potássio aplicadas via fertirrigação. Já Fontes et al. (2000) verificaram decréscimo do $\mathrm{pH}$ nos frutos de tomate quanto maior a dose de potássio aplicada em cobertura, demonstrando que o efeito pode variar de acordo com a espécie.

Em relação à acidez total titulável, houve redução linear em função das doses de potássio (figura 1C). Entretanto, também foi de pequena magnitude variando de 0,1129 a $0,0829 \%$, com redução de $0,0075 \%$ para cada $100 \mathrm{~kg}$ de $\mathrm{K}_{2} \mathrm{O}$ $\mathrm{ha}^{-1}$ aplicados em cobertura. Este resultado diverge do obtido por Grangeiro e Cecílio Filho (2004), em melancia (C. lanatus) que concluíram que as doses aplicadas no plantio $(50$ a $300 \mathrm{~kg}$ de $\mathrm{K}_{2} \mathrm{O}$ ha $^{-1}$ não influenciaram a acidez total titulável. Já Fontes et al. (2000) verificaram acréscimo de ácidos nos frutos de tomate, com o aumento das doses de potássio aplicadas por fertirrigação, 
ao contrário dos resultados obtidos neste trabalho com a abobrinha-de-moita.

Os ácidos orgânicos presentes nos tecidos vegetais encontram-se associados com seus sais de potássio e constituem sistemas tampões que regulam a atividade enzimática (Chitarra e Chitarra, 2005). Assim, maiores concentrações de potássio no suco celular demandam maior proporção de ácidos dissociados que devem estar presentes para garantir o equilíbrio de cargas negativas e positivas no meio (Malavolta, 2006), diferentemente do que foi observado em relação à abobrinha-de-moita em que o aumento do teor de potássio resultou na diminuição da acidez total titulável e aumento do $\mathrm{pH}$ nos frutos.

Não foi verificado efeito significativo das doses de potássio em cobertura para a característica sólidos solúveis totais nos frutos, demonstrando que, independente do tratamento, os frutos apresentaram valores médios de 4,94 ${ }^{\circ}$ Brix. Os sólidos solúveis totais correspondem a todas as substâncias que se encontram dissolvidas na água dos alimentos. Os açúcares acumulados constituem as principais substâncias químicas dos frutos, assim, quanto maior o teor de sólidos solúveis totais, maior o teor de açúcares no fruto (Chitarra e Chitarra, 2005) Grangeiro e Cecílio Filho (2004) e Vásquez et al. (2005) concluíram que as doses de potássio influenciaram o teor de SS em frutos de melancia (C. lanatus) e melão (C. melo), respectivamente. No entanto, o melão (C. melo) é um fruto maduro, em que os açúcares acumulam-se preferencialmente nos estádios finais de maturação (Godoy e Cardoso, 2003), enquanto a abobrinha (C.pepo) é um fruto imaturo, ainda com pequeno acúmulo de SST. Com o avanço da maturação existe a tendência de aumento do teor de açúcar. Assim frutos de melancia (C. lanatus) e melão (C. melo) que são colhidos maduros tendem a apresentar maiores teores de sólidos solúveis totais do que frutos de abobrinha-de-moita (C.pepo) cuja colheita é feita com frutos imaturos.
Verificou-se efeito significativo das doses de potássio para a relação sólidos solúveis totais por acidez total titulável ("ratio"), com elevação desta relação à medida que se aumentaram as doses de potássio em cobertura (figura 1D). Esta relação variou de 43 a 59, com aumento de 4 unidades para cada $100 \mathrm{~kg}$ de $\mathrm{K}_{2} \mathrm{O}$ ha $^{-1}$ aplicados em cobertura. Considerando-se que não houve influência nos SS, a elevação nesta relação ocorreu pela redução na acidez total titulável (figura 1C).

Em melancia (C. lanatus) sem sementes, Grangeiro e Cecílio Filho (2004) verificaram redução na relação sólidos solúveis totais pela acidez total titulável em função do aumento da concentração de potássio na solução nutritiva e incremento no teor de sólidos solúveis totais até a dose de 140 $\mathrm{kg}$ de $\mathrm{K}_{2} \mathrm{O}$ ha-1 com redução a partir desta dose. No entanto, Costa et al. (2004) concluíram que concentrações de potássio na solução nutritiva superiores a $66 \mathrm{mg} \mathrm{L}^{-1}$ não alteraram as características de teor de sólidos solúveis totais e da acidez total titulável em frutos de melão (C. melo).

A relação sólidos solúveis totais por acidez total titulável é uma das melhores formas de avaliação do sabor, sendo mais representativa que a medição isolada de açúcares ou da acidez (Chitarra e Chitarra, 2005). Entretanto, são desconhecidos padrões desta relação para a abobrinha (C. pepo), não sendo possível afirmar que houve melhora ou piora no sabor dos frutos, apenas que houve alteração.

Não foi verificado efeito significativo das doses de potássio para a característica açúcares redutores, com média de 3,01\%, demonstrando que as doses de potássio em cobertura estudadas não influenciaram esta característica de qualidade. Os açúcares redutores representam as concentrações de glicose e frutose no fruto, sendo bastante utilizados para a avaliação de doçura dos frutos. Porém, a colheita de abobrinha-de-moita é de frutos imaturos não resultando em grandes acúmulos de açúcares, talvez por isso os resulta- 
dos não apresentaram diferenças significativas, assim como para os SS.

Também não foi verificado efeito significativo das doses de potássio para a característica textura, com média de 2,54 N. A textura é o atributo físico de qualidade resultante dos constituintes estruturais dos frutos e pode indicar as transformações na estrutura celular, coesão das células e alterações bioquímicas, responsáveis pela textura do produto (Chitarra e Chitarra, 2005). Cardoso et al. (2007), avaliando a aplicação parcelada de doses de potássio e nitrogênio em batata inglesa, não observaram qualquer influência dos tratamentos na textura e no teor de açúcares redutores, resultados semelhantes aos obtidos neste trabalho. Já Grangeiro e Cecílio Filho (2004)

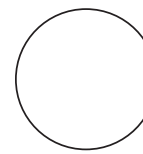

AOAC. 2005. Official methods of analysis of the Association of Official Analytical Chemistry. $18^{\text {th }}$ ed. Washington DC.

Araújo, H.S., B.R. Quadros, A.I.I. Cardoso e C.V. Corrêa. 2012. Doses de potássio em cobertura na cultura da abóbora. Pesqui. Agropecu. Trop. 42(4), 469-475.

Brady, N.C. 1989. Natureza e propriedades do solo. $7^{\text {a }}$ ed. Freitas Bastos, Rio de Janeiro, Brasil.

Brasil. 2005. Métodos físico-químícos para análise de alimentos. $4^{a}$ ed. Ministério da Saúde. Agência Nacional de Vigilância Sanitária, Brasília.

Cardoso, A.D., M.A.R. Alvarenga, T.L. Melo e A.E.S. Viana. 2007. Produtividade e qualidade de tubérculos de batata em função de doses e parcelamentos de nitrogênio e potássio. Ciênc. Agrotec. 31(6), 1729-1736.

Ceagesp (Companhia de Entrepostos e Armazéns Gerais de São Paulo). 2014. Sistemas de informação de mercado da companhia de entrepostos e armazéns gerais de São Paulo. Seção de Economia e Desenvolvimento. CEAGESP, São Paulo, Brasil.

Chitarra, M.I.F. e A.B. Chitarra. 2005. Pós-colheita de frutos e hortaliças. 2a ed. ESAL/FAEPE, Lavras, Brasil. concluíram que a espessura da casca dos frutos de melancia (C. lanatus) foi aumentada quanto maior a dose de potássio. Ressalta-se, novamente, que em abobrinha-de-moita colhem-se os frutos imaturos quando a superfície ainda é tenra, ao contrário da melancia (C. lanatus).

\section{CONCLUSÕES}

Conclui-se que as doses de potássio resultaram em aumento linear no teor de potássio, pH e o "ratio" (relação sólidos solúveis totais pela acidez total titulável) e redução linear na acidez total titulável dos frutos. As demais características químicas e físicas avaliadas não foram influenciadas pelas doses de potássio.

\section{REFERÊNCIAS BIBLIOGRÁFICAS}

Costa, C.C., A.B. Cecílio Filho, R.L. Cavarianni e J.C. Barbosa. 2004. Concentração de potássio na solução nutritiva e a qualidade e número de frutos de melão por planta em hidroponia. Ciênc. Rural 34(3), 731-736.

Filgueira, F.A.R. 2008. Novo manual de olericultura: agrotecnologia moderna na produção e comercialização de hortaliças. UFV, Viçosa, Brasil.

Fontes, P.C.R., R.A. Sampaio e L.F. Finger. 2000. Fruit size, mineral composition and quality of trickle: irrigated tomatoes as affect by potassium rates. Pesqui. Agropecu. Bras. 35(1), 21-25.

Godoy, A.R. e A.I.I. Cardoso. 2003. Curva de crescimento e qualidade de frutos de melão rendilhado sob cultivo protegido. Rev. Ceres 50(289), 303-314.

Godoy, A.R., A.C. Salata, C. Kano, A.R.O. Higuti, A.I.I. Cardoso e R.M. Evangelista. 2012. Produção e qualidade de couve-flor com diferentes doses de potássio em cobertura. Sci. Agrar. Paran. 11(2), 33-42.

Grangeiro, L.C. e A.B. Cecílio Filho. 2004. Qualidade de frutos de melancia sem sementes em função de fontes e doses de potássio. Ciênc. Agrotec. 28(3), 570-576.

Kumar, P., S.K. Pandey, B.P. Singh, S.V. Singh e D. Kumar. 2007. Influence of source and time of potas- 
sium application on potato growth, yield, economics and crisp quality. Potato Res. 50, 1-13.

Malavolta, E. 2006. Manual de nutrição mineral de plantas. Agronômica Ceres, São Paulo, Brasil.

Malavolta, E., G.C. Vitti e A.S. Oliveira. 1997. Avaliação do estado nutricional das plantas, princípios e aplicações. Potafós, Piracicaba, Brasil.

Melo, A.S., M.E.B. Brito, J.D.M. Dantas, C.D. Silva Junior, P.D. Fernandes e L.V. Bonfim. 2008. Produção e qualidade do pimentão amarelo sob diferentes níveis de potássio em ambiente protegido. Rev. Bras. Ciênc. Agrár. 4, 17-21.

Minerais. 2009. Só nutrição. Em: www.sonutricao.com. br/conteudo/micronutrientes/p4.php; acesso 19 de março de 2009 .

Nelson, N.A. 1944. Photometria adaptation of Somogi method for determination of glicose. J. Biol. Chem. 153(2), 375-380.
Salata, A.C., C. Kano, A.R. Godoy, R.M. Evangelista e A.I.I. Cardoso. 2011. Produção e qualidade de frutos de ervilha torta submetidas a diferentes níveis de adubação potássica. Nucleus 8(2), 127134.

Trani, P.E. e B.V. Raij. 1997. Hortaliças. Em: Raij, B.V., H. Cantarella, J.A. Quagio e A.M.C. Furlani (Org.) Recomendações de adubação e calagem para o Estado de São Paulo. Instituto Agronômico e Fundação IAC, Campinas, Brasil.

Vásquez, M.A.N., M.V. Folegati, N.S. Dias e V.F. Souza. 2005. Qualidade pós-colheita de frutos de meloeiro fertirrigado com diferentes doses de potássio e laminas de irrigação. Rev. Bras. Eng. Agríc. Ambient. 9(2), 199-204.

Vidigal, S.M., D.D. Pacheco e C.E. Facion. 2007. Crescimento e acúmulo de nutrientes pela abóbora híbrida tipo tetsukabuto. Hortic. Bras. 25(3), 375 380. Doi: 10.1590/S0102-05362007000300011 